\title{
Mapping and Evaluating Regional University-Industry Knowledge Flow through Patent Licensing
}

\author{
Xiaopei Gao, Yuming Chen, Wei Song, Xiaobao Peng, Xiaoyan Song \\ School of Public Affairs, University of Science \& Technology of China, Hefei, China \\ Email: gxp0406@mail.ustc.edu.cn
}

Received 20 November 2014; revised 20 December 2014; accepted 28 December 2014

Copyright $@ 2015$ by authors and Scientific Research Publishing Inc.

This work is licensed under the Creative Commons Attribution International License (CC BY).

http://creativecommons.org/licenses/by/4.0/

(c) (i) Open Access

\begin{abstract}
Different regions had various kinds of academic resources and industries competitors. The knowledge and innovation output generated by researchers in academy had been transferred into industries through patent licensing. Using the patent licensing document analyzing method and the mapping technique, the academic-industry knowledge flowing patterns of different regions in China had been discovered and visualized in maps. The regional performance of academic-industry knowledge transfer was rather mixed and unbalanced. Based on the licensing performance data, this paper had also generated a $4 \times 4$ block matrix as evaluation tool and ranked 28 Chinese regions into 8 levels according to their academic licensing performance. Further suggestions and advice had been given for regions in different levels.
\end{abstract}

\section{Keywords}

Knowledge Transfer, University-Industry, Patent, Licensing, Knowledge Flow, China

\section{Introduction}

In the perspective of open innovation, firms should utilize resources and paths to markets from both inside and outside firm boundaries [1]. Academic inventions generated by universities and colleges had been considered one of the main source of external knowledge to companies in private sectors [2] [3]. Scientific researches in universities could bring basic knowledge support for companies and some byproducts of scientific research could be applied in the industry practice. Therefore, inventions generated by universities and colleges had been transferred into industries through various channels [2] [4]-[6], including publications, patenting, licensing, conferences, consulting, joint ventures, personnel exchange, scientist migration to the private sectors and so on. 
Through these various channels, patenting and licensing had acquired most attentions in both legislative practices and academic research [7] [8].

Licensing is one of the crucial ways of universities scientific knowledge transfer and had gained much attention on the practice [7] [8]. Compared with other channels of the scientific knowledge transfer, licensing involves those academic outputs that are much closer to the stage of commercialization. Private companies have the intention to pursue more profits through acquiring new technologies. They will sign a licensing contract with universities and pay royalties only for those technologies that can be applied on the production process and make profits for the companies. Patents which have been licensed through licensing channels are closer to the commercialization process. Licensing is a crucial way for companies to gain direct and applicable frontier technology from the academic world.

The scientific knowledge and technology transferring process involve a large number of interactions among partners. Transferring of knowledge, especially tacit knowledge which could not be interpreted in a codified way, require direct interactions and communications noted as "learning by doing" [9] and "learning by using" [10]. Since the interactions among partners would be affected by the geographic distance of partners, the knowledge transferring process would be constrained by distance too. In the knowledge transferring between universities and industries, the impact of geography had been highlighted by previous works. However, results on the influence of geographic factors on academic knowledge transferring are rather mixed [11]. Some works had supported the impact of geographic proximity and suggested that firms located near public research institutions could gain more benefits through knowledge transferring process [12]-[14]. However, results in other works had suggested that the impact of distance was not as significant as expected [11] [15] [16].

As companies were seeking to gain access to external scientific knowledge and resources, different forms of relational networks had formed to strengthen interactions and communication. Industry districts, defined as "a network comprising independent firms operating in the same or related market segment and a shared geographic locality, benefiting from external economies of scale and scope from agglomeration” [17], consist of a network of producer, supporting organizations, and a local labor market [18]. In the context of industrial districts, companies tend to set their office near prominent universities and partners. Industry firms could draw advantage from nearby academic centers [19]. The basic logic behind this phenomenon is that the distance can have negative effect on the transferring of knowledge. Universities tend to transfer more knowledge and technology to local companies. However, previous studies about the negative effects of geographic distance are rather mixed. Whether the knowledge transferring process reveal a localized feature, especially in newly developing economies like China, had significant effect on the government policies for the following reasons: 1) Most universities in China were publicly funded. The funds were mostly provided by central government or local government. The knowledge transferring directions of local universities would affect the fund provision, for the local government would give more resources to universities that have made more contribution to the local economy. 2) Different regions had various kinds and volumes of academic resources, thus could reveal different patterns on the local knowledge exchange. 3) The regional difference of university-industry knowledge transferring patterns could provide insides on the national innovation policies. Different support and resources should be deployed in regions with different patterns.

This paper had investigated the regional university-industry knowledge flow in China through academic patent licensing data. This paper had made two contributions: First, it had investigated the regional academic-industry patent licensing performance and variances in China. Patterns of academic patent licensing in different districts had been discovered and summarized in visual maps. Second, it had generated a set of block matrix as evaluation tool to analyzing each region's academic licensing performance and ranked those Chinese regions into 8 levels. The block matrix method generated in this work had provided a multi-dimensional way to look into the regional academic knowledge transferring capacity, which not only had capture the total amount of knowledge transferring in both directions, but also had taken local transferring portions into account. Suggestions and advices had been provided to regions in different level of performance.

\section{Data \& Methods}

The patent licensing document of all Chinese universities from 2002 to 2012 had been acquired from State Intellectual Property Office of the P.R.C. In the year of 2002, a law had been enacted to enforce the patent licensing activities been recorded on the national patent system. Only those documents that had been listed in the sys- 
tem would be protected by the national law. So the dataset could only be dated back to 2002. In the patent document, the licensor, licensee, territory, filing date and patent no. had been recorded. In this study, we only focus on the patents licensed from universities to industries. 5688 licensing documents had been identified from the dataset. This is the number of academic licensing activities that had actually taken place. In this dataset, 354 universities and 4059 enterprises had been detected. This data revealed that only 354 universities in China had commercialized academic patents through licensing. Since there had been more than 2000 universities and colleges in China, 354 is a really small amount of the total. In the 5688 documents, 2 documents were patents licensed form Jinan University to a Japanese company named Shinjiro Torii.inc. Since our research focus is on the within national boarder of geographic variance, patents licensed to foreign companies would not be considered in data. So the final volume of licensing documents is 5686.

To generate insights in the regional licensing patterns, the social network perspective had been applied to look into the relationship of different districts. Each universities and companies on the licensor and licensee positions had been replace by their provincial location. For example, Peking University had licensed a patent to Founder Group.inc. Since Peking University and Founder Group Inc. are located in Beijing, this will generate one licensing relationship from Beijing to Beijing, noted as local licensing. By such method, the 5686 licensing documents had been transferred into a relational dataset of 28 regions, with directions in each relationship (representing the direction of knowledge flow). Other regions in China, including Tibet, Qinghai, Ningxia, Taiwan, Hongkong and Macau, had not involved in academic patent licensing in this dataset. The following results were based on the transformed dataset. Compared with patent collaboration data used in Hong (2008) and Gao et al. (2011)'s work, patent licensing data used in this paper had knowledge flowing directions embedded. A patent licensed from region A to region B does not equal to a patent licensed from region B to region A. Therefore the results could reveal the actual knowledge transferring trend in the academic-industry relationship.

To generate more clear view on the academic-industry knowledge flowing patterns, maps of Chinese academic regional licensing had been made by the open source software Gephi. This software was mainly used in social network analysis to visualize relational data. Since the licensing data between regions were also relational data, we had used Gephi to visualize the regional knowledge flow. The Chinese map in the diagram was generated by a Gephi plugin named Map of Countries (https://marketplace.gephi.org/plugin/maps-of-countries/).

\section{Results}

\subsection{Regional Knowledge Flow Patterns}

Table 1 had shown the basic results of patent licensing document analyzing. The total out-licensing data in the fifth column represented the total volume of patents generated by universities in ego region that had been transferred to industry by the channel of licensing. Regions that obtained large number in total out-licensing had more academic researchers that were actively engaged in technology transfer activities. The total in-licensing data in the sixth column represented the total volume of patents that had been transferred into companies in ego regions, which indicated industries' absorptive capabilities of academic inventions. Local licensing data in the second column represented the total volume of patents that had been transferred from universities to companies in the same ego district. Numbers in this category had two implications. First, they indicated the knowledge contribution of universities to the local economy. Second, they indicated the efficiency of local knowledge utilization of industries. The seventh column and eighth column had shown the ratio of local-licensing in total out-licensing and total in-licensing. Non-local out-licensing data in the third column represented the number of patents transferred from local universities to non-local industries and non-local in-licensing data in the fourth column represented the number of patents transferred from non-local universities to the local industries. These data had been used to measure the licensing volume of these regions. Some regions had involved actively in each indicator and some regions had performed badly.

Besides the number of licensing activities between two regions, the knowledge transferring directions also mattered. Mapping method had been used to illustrate the regional knowledge flow patterns, as shown in Figures 1-4. Each node in these figures represented each region. The size of node represented the relative amount of patent licensing activities the region had engaged. A solid line was used to represent the knowledge transferring relationship and the arrow was used to represent transferring direction. The thickness of edges represented the amount of knowledge transferred through this relationship. Figure 1 had shown the total knowledge flow 
Table 1. Basic statistical results of regional patent licensing.

\begin{tabular}{|c|c|c|c|c|c|c|c|c|c|}
\hline Province & $\begin{array}{c}\text { Local } \\
\text { licensing }\end{array}$ & $\begin{array}{l}\text { Non-local } \\
\text { out licensing }\end{array}$ & $\begin{array}{l}\text { Non-local } \\
\text { In licensing }\end{array}$ & $\begin{array}{l}\text { Total out } \\
\text { licensing }\end{array}$ & $\begin{array}{c}\text { Total in } \\
\text { licensing }\end{array}$ & $\begin{array}{l}\text { Local out } \\
\text { licensing } \\
\text { ratio }\end{array}$ & $\begin{array}{l}\text { Local in } \\
\text { licensing } \\
\text { ratio }\end{array}$ & Out degree & In degree \\
\hline Anhui & 293 & 15 & 86 & 308 & 379 & $95.13 \%$ & $77.31 \%$ & 5 & 12 \\
\hline Beijing & 138 & 275 & 87 & 413 & 225 & $33.41 \%$ & $61.33 \%$ & 19 & 14 \\
\hline Chongqing & 64 & 73 & 7 & 137 & 71 & $46.72 \%$ & $90.14 \%$ & 11 & 1 \\
\hline Fujian & 104 & 13 & 103 & 117 & 207 & $88.89 \%$ & $50.24 \%$ & 4 & 13 \\
\hline Gansu & 3 & 18 & 3 & 21 & 6 & $14.29 \%$ & $50.00 \%$ & 4 & 1 \\
\hline Guangdong & 386 & 83 & 517 & 469 & 903 & $82.30 \%$ & $42.75 \%$ & 11 & 22 \\
\hline Guangxi & 19 & 19 & 53 & 38 & 72 & $50.00 \%$ & $26.39 \%$ & 3 & 11 \\
\hline Guizhou & 3 & 7 & 5 & 10 & 8 & $30.00 \%$ & $37.50 \%$ & 2 & 1 \\
\hline Hainan & 0 & 0 & 13 & 0 & 13 & $0.00 \%$ & $0.00 \%$ & 0 & 3 \\
\hline Hebei & 81 & 38 & 103 & 119 & 184 & $68.07 \%$ & $44.02 \%$ & 7 & 12 \\
\hline Heilongjiang & 73 & 118 & 16 & 191 & 89 & $38.22 \%$ & $82.02 \%$ & 11 & 4 \\
\hline Henan & 19 & 38 & 39 & 57 & 58 & $33.33 \%$ & $32.76 \%$ & 8 & 9 \\
\hline Hubei & 122 & 118 & 86 & 240 & 208 & $50.83 \%$ & $58.65 \%$ & 10 & 17 \\
\hline Hunan & 118 & 58 & 73 & 176 & 191 & $67.05 \%$ & $61.78 \%$ & 11 & 15 \\
\hline Jiangsu & 818 & 262 & 598 & 1080 & 1416 & $75.74 \%$ & $57.77 \%$ & 21 & 21 \\
\hline Jiangxi & 9 & 14 & 15 & 23 & 24 & $39.13 \%$ & $37.50 \%$ & 3 & 3 \\
\hline Jilin & 34 & 28 & 10 & 62 & 44 & $54.84 \%$ & $77.27 \%$ & 6 & 3 \\
\hline Liaoning & 47 & 59 & 24 & 106 & 71 & $44.34 \%$ & $66.20 \%$ & 11 & 7 \\
\hline Neimenggu & 8 & 2 & 15 & 10 & 23 & $80.00 \%$ & $34.78 \%$ & 0 & 4 \\
\hline Shaanxi & 68 & 231 & 5 & 299 & 73 & $22.74 \%$ & $93.15 \%$ & 17 & 1 \\
\hline Shandong & 146 & 83 & 147 & 229 & 293 & $63.76 \%$ & $49.83 \%$ & 10 & 14 \\
\hline Shanghai & 158 & 422 & 76 & 580 & 234 & $27.24 \%$ & $67.52 \%$ & 17 & 12 \\
\hline Shanxi & 14 & 79 & 11 & 93 & 25 & $15.05 \%$ & $56.00 \%$ & 5 & 2 \\
\hline Sichuan & 55 & 82 & 33 & 137 & 88 & $40.15 \%$ & $62.50 \%$ & 11 & 7 \\
\hline Tianjin & 122 & 181 & 22 & 303 & 144 & $40.26 \%$ & $84.72 \%$ & 15 & 5 \\
\hline Xinjiang & 2 & 0 & 8 & 2 & 10 & $100.00 \%$ & $20.00 \%$ & 0 & 2 \\
\hline Yunnan & 14 & 13 & 12 & 27 & 26 & $51.85 \%$ & $53.85 \%$ & 1 & 3 \\
\hline Zhejiang & 273 & 160 & 322 & 433 & 595 & $63.05 \%$ & $45.88 \%$ & 16 & 20 \\
\hline
\end{tabular}

patterns of each region. Figures 2-4 were generated to reveal the local knowledge flow, regional knowledge out-flows, regional knowledge in-flows patterns in Figure 1. Therefore, Figures 2-4 were the subset of Figure 1.

In Figure 1, according to the size of nodes, Jiangsu, Guangdong, Zhejiang, Shanghai and Beijing had been engaged in academic patents licensing activities more frequently than other regions. Large amount of patent knowledge had been transferring among them based on the thickness of lines. In Figure 2, local knowledge flow map, the patents licensed in local area (with self loop) were of large numbers in Jiangsu, Guangdong, Anhui, Zhejiang and Shanghai. In Figure 3, the size of node represented the amount of knowledge transferred from 


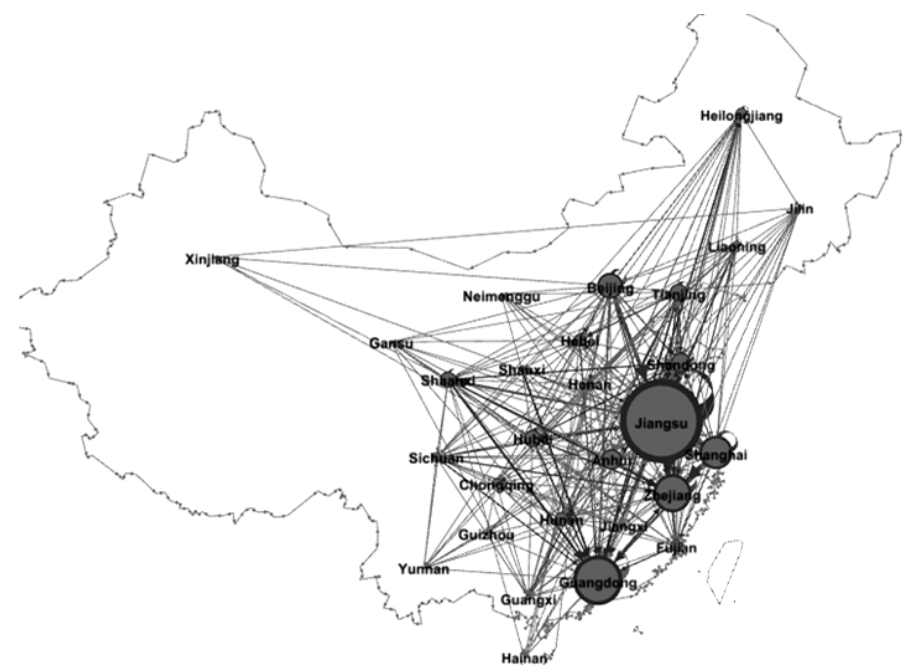

Figure 1. Total knowledge flow map.

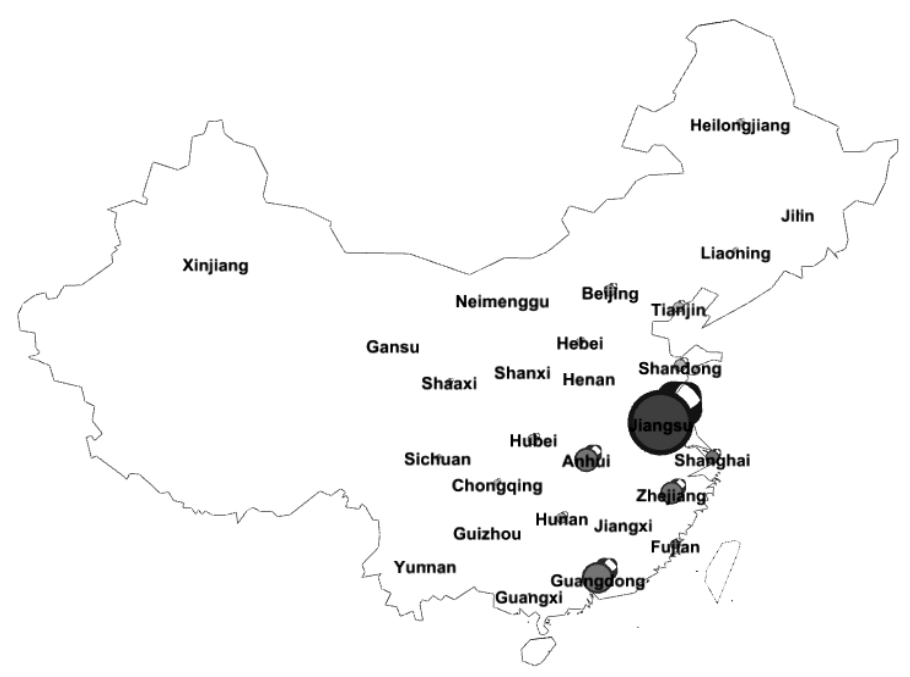

Figure 2. Local knowledge flow map.

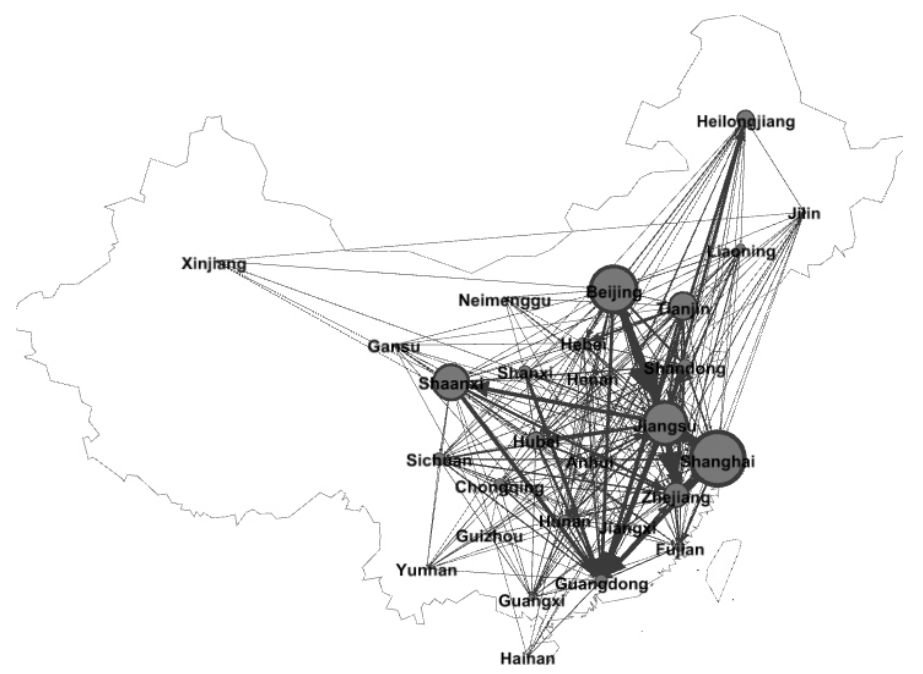

Figure 3. Regional knowledge out-flow map. 


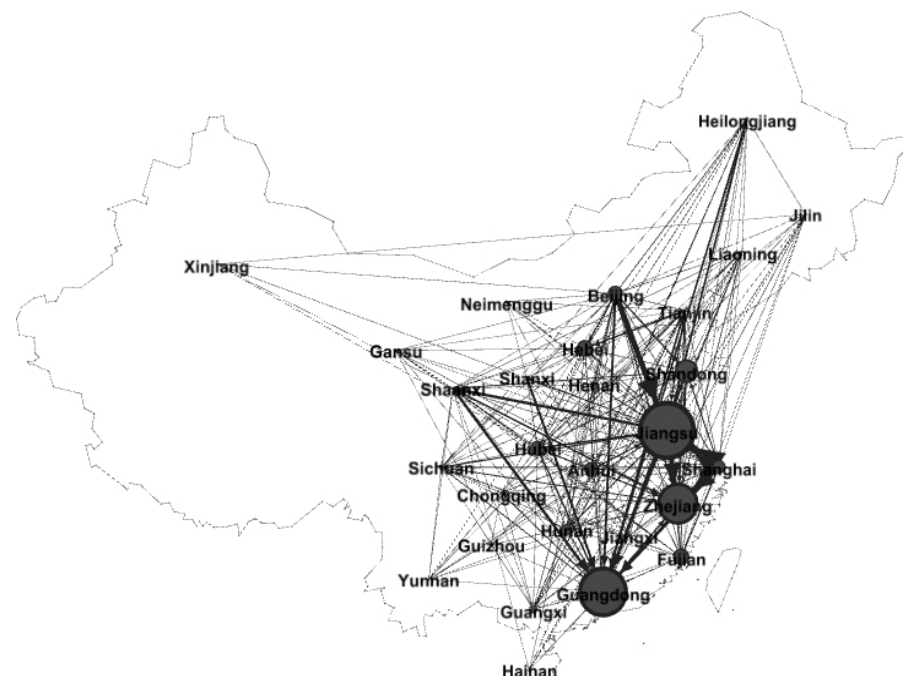

Figure 4. Regional knowledge in-flow map.

certain regions' universities. In Figure 4, the size of node represented the amount of knowledge transferred into certain regions' industries. As depicted in these two figures, Shanghai, Beijing, Jiangsu and Shaanxi had been the main source of outside academic knowledge whereas Jiangsu, Guangdong and Zhejiang had been the main recipient of outside academic knowledge. Knowledge exchanging among these regions had been more frequent than among other regions.

To investigate the diversification of regional knowledge flow, the degree centrality of each region had been generated in Table 1. The out degree data reflected the number of recipient regions (beside ego) that ego region had transferred knowledge to. It represented the knowledge spreading diversification of local universities. The in degree data reflected the number of academic sources that ego regional industry had absorbed from. Some regions, like Jiangsu, Beijing and Zhejiang, had relative large out degree and in degree. These regions had diversified knowledge transferring channels in both directions. Some regions, like Shaanxi, Tianjin and Heilongjiang, had relative large out degree but small in degree. Universities in these regions had more channel to transferring knowledge, but industries in these regions had relative few channels to absorb academic knowledge. Some regions, like Zhejiang, Shandong and Hubei, had relative few out degree but large in degree. Universities in these regions had fewer channels to spreading knowledge and industries in these regions had more channels to acquire academic innovation outcomes. Some other regions like Guizhou, Yunnan, Hainan, Neimenggu and Xinjiang, had relative few out degree and in degree. These regions had involved less in cross boarder academic knowledge transferring activities.

\subsection{Evaluating Regional Academic Licensing Performance}

Previous paragraph had analyzed the performance of academic patent licensing in each Chinese region. Some regions had been involved more in this knowledge transferring process and some region had not. With abundant analytical results, the problem had arisen: How to evaluate these results? How could we assert that one region had performed better than other region?

In the public policy perspective, the more knowledge transferring activities occurred, the more benefit certain regions could acquire through this process. Thus, a large out-licensing number (as knowledge resource) and large in-licensing number (as knowledge recipient) would be preferred. However, the portion of patents licensed within regional boundaries also mattered. Previous studies had underlined the importance of interactions and communications in knowledge transferring success. Local patent licensing activities could assure the intensity of large scale communication and interactions among licensors and licensees. Therefore, the more portion of knowledge been transferred in local area, the more success would occur.

In order to capture these two characteristics simultaneously, a set of measurement had been generated to evaluate each region's performance. First, the 28 regions had been classified into 4 groups based on their total out-licensing numbers and total in-licensing numbers. This measurement was used to reveal patterns in total 
knowledge flows. Second, the 28 regions had been classified into another 4 groups based on their local out-licensing ratio and local in-licensing ratio. This measurement was used to reveal patterns in local transferring portion. Finally, a $4 \times 4$ block matrix had been generated based on the 2 sets of groups. Each region would be fitted in one block and the performance of regional academic licensing activities would be evaluated based on this matrix.

A scatter plot of total in-licensing numbers and total out-licensing numbers had been shown in Figure 5 . The vertical line and horizontal line in the diagram represented the mean value (202.86) in two axes. The two lines had divided these regions into 4 groups (as shown in Table 2). The first group (Group T1), consisting of 8 regions, had up-average value in both total out-licensing numbers and total in-licensing numbers. The second group (Group T2) with 2 group members was up average in total out-licensing but under average in total in-licensing. The third group (Group T3), with only one group member, was under average in total out-licensing but up average in total in-licensing. The fourth group (Group T4), the largest group with 17 members, was under average in both total out-licensing numbers and total in-licensing numbers. Since our research had mainly focused on academic licensing activities, the out-licensing performance was relatively more important than the in-licensing performance. So regions in Group T2 would be considered as better performed than regions in Group T3.

A scatter plot of local in-licensing ratio and local out-licensing ratio of 28 regions had been shown in Figure 6. The vertical line and horizontal line in the diagram represented $50 \%$ in both axes. The two lines had divided these regions into another 4 groups (as shown in Table 3). The first group (Group L1), consisting of 7 regions, had over 50\% in both local out-licensing ratio and local in-licensing ratio. The second group (Group L2), with 6 group members, was over $50 \%$ in local out-licensing ratio but fewer than $50 \%$ in local in-licensing ratio. The third group (Group L3), the largest group with 9 members, was fewer than $50 \%$ in local out-licensing ratio but over 50\% in local in-licensing ratio. The fourth group (Group L4), with 6 members, was fewer than 50\% in both

Table 2. Group members in total licensing numbers.

\begin{tabular}{ll}
\hline & \\
\hline Group T1 & Jiangsu, Guangdong, Anhui, Zhejiang, Shanghai, Shandong, Beijing, Hubei \\
Group T2 & Tianjin, Shaanxi \\
Group T3 & Fujian \\
& $\begin{array}{l}\text { Hunan, Hebei, Heilongjiang, Chongqing, Sichuan, Liaoning, Jilin, Guangxi, Henan, } \\
\text { Group T4 }\end{array}$
\end{tabular}

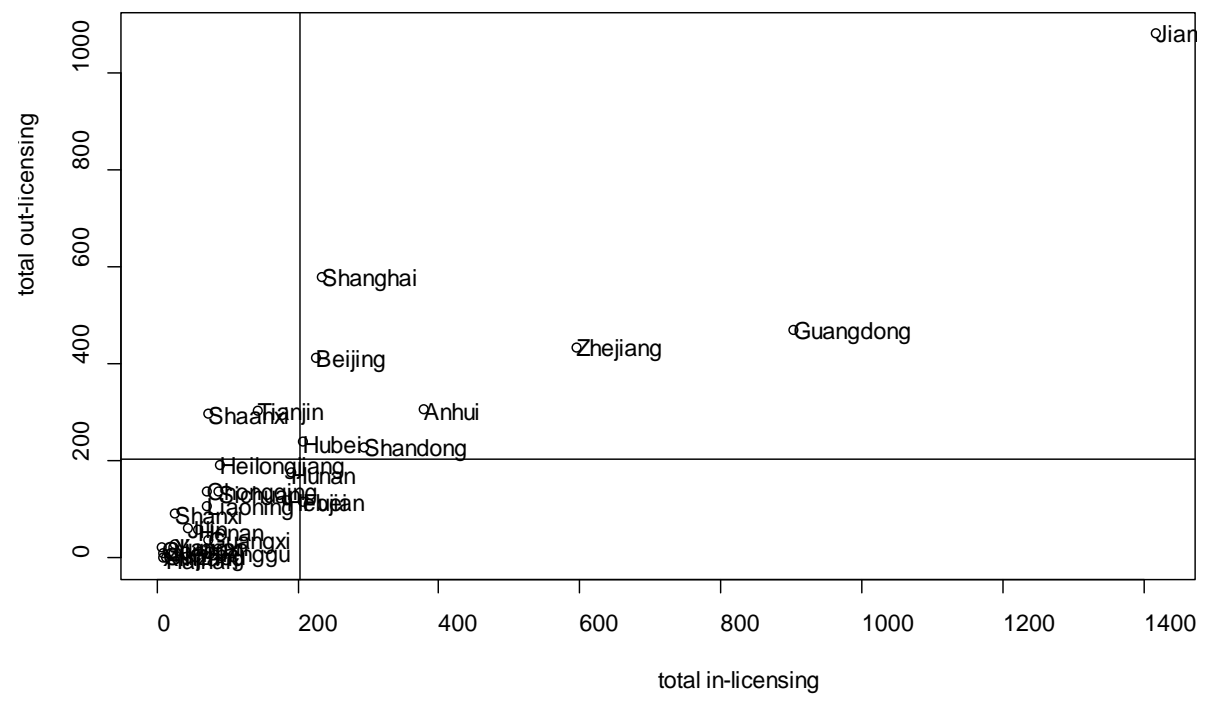

Figure 5. Total in-licensing numbers and total out-licensing numbers. 


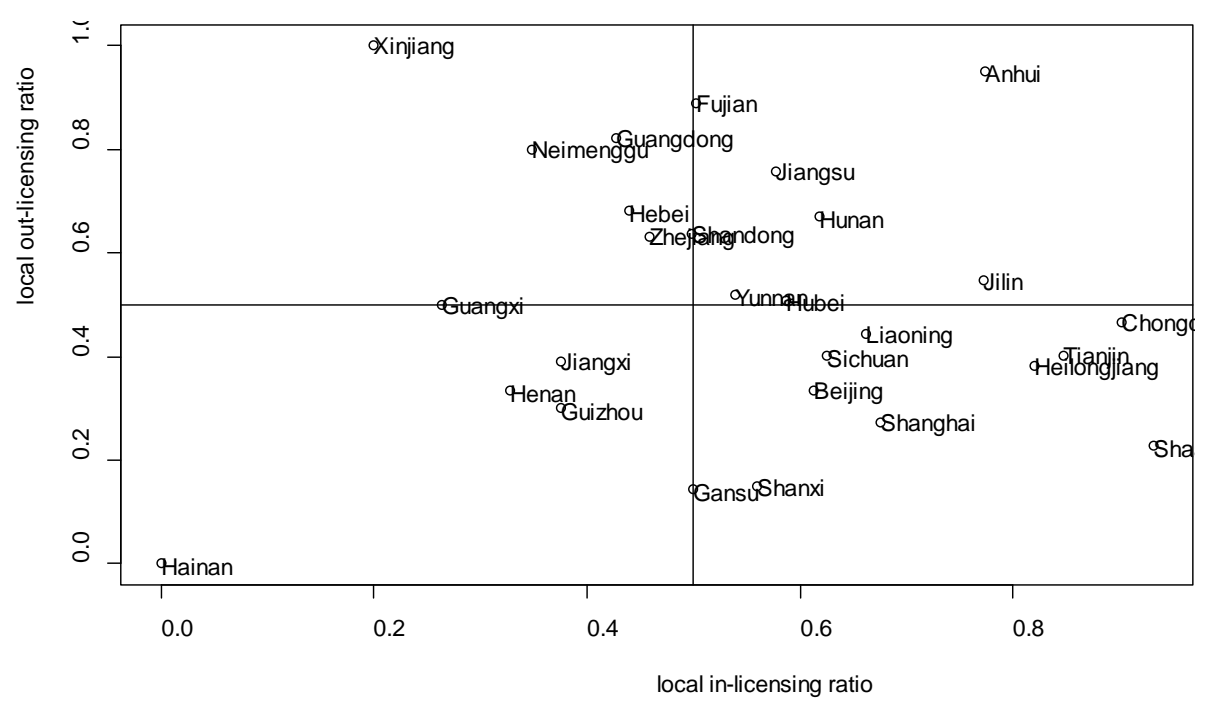

Figure 6. Local in-licensing ratio and local out-licensing ratio.

Table 3. Group members in local licensing ratio.

\begin{tabular}{ll}
\hline & \multicolumn{1}{c}{ Members } \\
\hline Group L1 & Anhui, Fujian, Hubei, Hunan, Jiangsu, Jilin, Yunnan \\
Group L2 & Guangdong, Hebei, Neimenggu, Shandong, Xinjiang, Zhejiang \\
Group L3 & Beijing, Chongqing, Heilongjiang, Liaoning, Shaanxi, Shanghai, Shanxi, Sichuan, Tianjin \\
Group L4 & Gansu, Guangxi, Guizhou, Hainan, Henan, Jiangxi \\
\hline
\end{tabular}

local out-licensing ratio and local in-licensing ratio. The reason that Group L2 rank highly than Group L3 is the same as in the Group T2 and Group T3.

Based on the 2 sets of groups, a $4 \times 4$ block matrix had been generated, with the $\mathrm{x}$ axis indicating the L1 to L4 groups and the y axis indicating the T1 to T4 groups (in Figure 7). There were 16 cells in the matrix and the 28 regions had been fixed into 9 of the 16 regions. Each cell represented different levels of performance. For example, the L1-T1 cell in the up right corner consisted of regions that performed excellent in both licensing numbers and licensing ratios. Anhui, Hubei and Jiangsu had high level of out-licensing and in-licensing numbers as well as more than half percent of local out-licensing and local in-licensing ratio. The L4-T4 cell in the down left side of the matrix consisted of regions that performed poorly in both licensing numbers and licensing ratios. Gansu, Guangxi, Guizhou, Hainan, Henan and Jiangxi, most of which were less developed regions in China, had low level of out-licensing and in-licensing numbers as well as less than half percent of local out-licensing and local in-licensing ratio. These regions had a lot of work to do to improve the academic-industry knowledge transferring performance.

Base on this matrix, the regional academic-industry licensing performance could be further developed into 8 levels. Regions in first ranked levels had better performance than regions in second ranked levels.

1st level: (L1-T1) Anhui, Hubei, Jiangsu.

2nd level: (L2-T1) Guangdong, Shandong, Zhejiang.

3rd level: (L3-T1) Beijing, Shanghai; (L1-T3) Fujian.

4th level: (L3-T2) Shaanxi, Tianjin.

5th level: (L1-T4) Hunan, Jilin, Yunnan.

6th level: (L2-T4) Hebei, Neimenggu, Xinjiang.

7th level: (L3-T4) Chongqing, Heilongjiang, Liaoning, Shanxi.

8th level: (L4-T4) Gansu, Guangxi, Guizhou, Hainan, Henan, Jiangxi.

The implications of these results and advices for policy making would be discussed in the following section. 


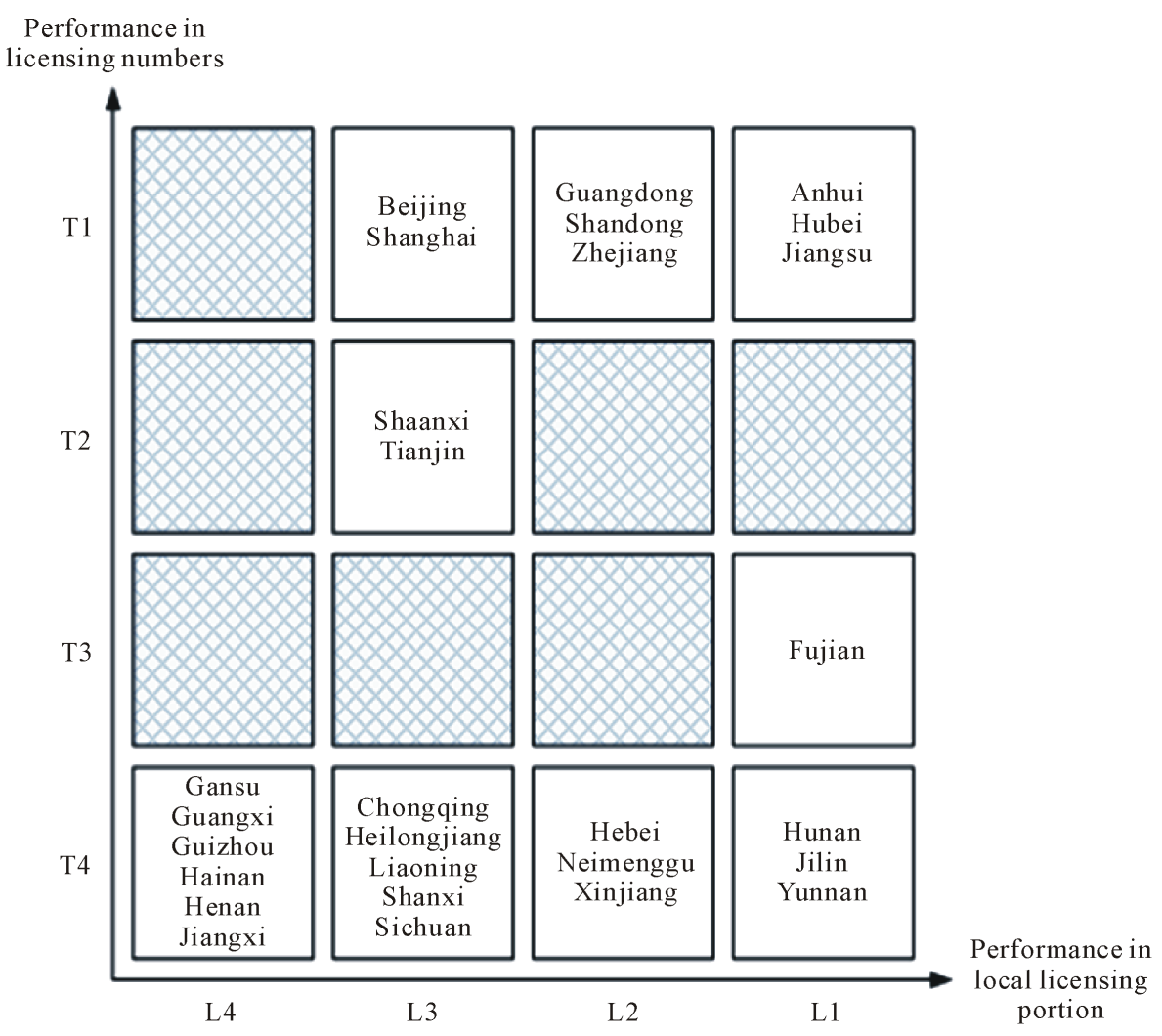

Figure 7. Licensing performance evaluation matrix.

\section{Discussion}

The licensing performance evaluation matrix had used the patent licensing numbers and patent local licensing ratio to evaluate regional performance. The 28 regions had been classified into 8 levels according to their performance.

1st level. Regions in this level had the best performance in the 28 regions. Universities and industries in Anhui, Hubei and Jiangsu had been actively engaged in academic-industry knowledge transferring. Universities had transferred large portion of knowledge to local industries and companies in local industries had mainly absorbed technology and inventions from local universities. Sustainable knowledge transferring relationships had been established within these regions.

2nd level. Regions in this level also had large number of out-licensing and in-licensing, which means active engagement of local universities and industries in the knowledge transferring process. Compared with regions in 1st level, these regions had less than $50 \%$ of in-licensing ratio but larger than $50 \%$ of out-licensing. This indicated that the amount of academic knowledge generated in local universities were not enough to satisfy the need of local industries so that local companies had to seek technologies from outside academies. In this circumstance, more academic resources should be invested and the innovation production of universities in Guangdong, Shandong and Zhejiang should be improved to satisfy the growing needs for local technologies.

3rd level. There were 2 sets of regions in this level. The first set included Beijing and Shanghai and the second set included Fujian. In the first set, Beijing and Shanghai also had large number of out-licensing and in-licensing. Compared with regions in 1st level, Beijing and Shanghai had less than $50 \%$ of out-licensing ratio but more than $50 \%$ of in-licensing ratio. In this case, universities in these regions had provided more knowledge than the local industries could digest so that the extra knowledge had been flowing into other regions. In practice, Beijing and Shanghai are the center city of higher education and had occupied the largest amount of academic resources than any other regions. To improve regional licensing performance, companies in Beijing and Shanghai should improve their absorptive capacities and making good use of local academic resources. The second set of region in 3rd level is Fujian, which had more than $50 \%$ ratio in both local out-licensing and local in-licensing, 
but not well performed in the licensing numbers. The in-licensing number of Fujian had exceeded the average value, but the out-licensing number was under average. More patents had been absorbed into Fujian to meet the technological demand of local companies. In that case, the efficiency of knowledge production in local universities should be improved to provide more patents to the local industries.

4th level. Shaanxi and Tianjin were in the 4th level. They had up average number of out-licensing but with under average number of in-licensing, as well as more than $50 \%$ ratio in local in-licensing and less than $50 \%$ ratio in local out-licensing. A larger out-licensing number and a less in-licensing number indicated the amount of knowledge provided in local universities had exceeded the amount of knowledge received in local industries. Companies in these regions had not involved actively in the academic knowledge transferring process. A larger local in-licensing ratio and a less local out-licensing ratio indicated that large portion of knowledge had been transferred into other regions. In that case, companies in these regions should promote engagement in academic knowledge transferring process at the very first step.

5th level. Hunan, Jilin and Yunnnan were in the 5th level. Like Fujian in the 3rd level, they had more than 50\% ratio in both local out-licensing and local in-licensing. But their performance in licensing number was worse than the 3rd level. The number of out-licensing and in-licensing were both less than average in these regions. The low level of licensing number and high level of local licensing ratio indicated that the small amount of knowledge were mainly flowing between local universities and local industries. Universities as main academic resources and companies as main technology recipients should both take actions to promote the amount of academic knowledge flow within area and cross border.

6th level. Hebei, Neimenggu, Xinjiang were in the 6th level. The numbers of out-licensing and in-licensing were also under average in this level. The ratio of local out-licensing was larger than $50 \%$ but the ratio of local in-licensing was less than $50 \%$. This indicated that the knowledge generated in local universities could not satisfy the technological needs of local industries. To improve regional performance, the total knowledge flowing amount should be promoted, especially the mount of applicable inventions produced by universities.

7th level. Chongqing, Heilongjiang, Liaoning, Shanxi were in the 7th level. Compared with Beijing, Shanghai, Shaanxi and Tianjin, the number of out-licensing and in-licensing were both under average in these regions. At the mean time, the ratio of local in-licensing was larger than $50 \%$ but the ratio of local out-licensing was less than 50\%. Despite the relative few amount of knowledge transferring around, universities in these regions had licensed more patents to other regions. The absorptive capacity of local companies should be promoted and universities and industries should engage more in the innovation exchange activities.

8th level. Regions in this level had the worst performance in the 28 regions. Universities and industries in Gansu, Guangxi, Guizhou, Hainan, Henan and Jiangxi had merely engaged in academic-industry knowledge transferring. Little academic knowledge had been flowing among these regions and the minority of them had either been transferred to outside industries or received from outside universities. The first step in improving academic licensing performance is to establish knowledge exchange relationships between universities and industries. Universities should improve the quality and quantity of patents and companies in local industries should seek more resources from outside resources. There would be a long way for these regions to improve academic licensing performance.

\section{Conclusions}

Performance of regional academic patent licensing had been evaluated in multiple dimensions. A $4 \times 4$ block matrix had been generated to evaluate regional academic licensing performance, considering both the amount of licensing and the portion of localized licensing in each direction. This method had been used in Boston Matrix to analyze business unit [20]. By this method, the 28 Chinese regions had been ranked into 8 levels according to their performance in both dimensions. We could spot regions like Anhui, Hubei and Jiangsu, which had the relative best performance. The performance of Anhui and Hubei were beyond expectation for they had exceeded the performance of other more economically developed regions like Shanghai and Beijing. The economic performance could not secure the knowledge transferring performance We could also spot regions like Gansu, Guangxi, Guizhou, Hainan, Henan and Jiangxi, which had huge gaps in knowledge sharing compared with other regions. Different suggestions and advices had been made to regions in different levels in the Discussion section in details. For regions like Guangdong, Shandong and Zhejiang, the main improvement should be made is to promote local academic knowledge production, especially the production of applicable scientific outputs. For 
regions like Beijing and Shanghai, which had transferred great amount of knowledge into external regions, should make efforts to promote absorptive capacity of local industries and encourage local companies to acquire knowledge and technologies from local academies. There were also other regions which should promote the amount of interactions and communications between universities and industries in the first place. The public policy concerning this interaction should be based on the different patterns in each region.

We sincerely hope that findings in this paper could provide some hints and insights into the research field of university-industry linkages as well as in the public policy perspectives. Future research on the university-industry licensing activities could explore the main reasons and logics behind those variance performances and we are hoping to make more contribution in this phenomenon.

\section{Acknowledgements}

This work was supported by the National Natural Science Foundation of China under Grant Nos. 71202054, the Soft Science Research Project of Anhui Province of China under Grant Nos. 1402052002, and "The Fundamental Research Funds for the Central Universities.”

\section{References}

[1] Chesbrough, H.W. (2003) Open Innovation: The New Imperative for Creating and Profiting from Technology, Harvard Business Press, Boston.

[2] Agrawal, A. (2001) University-to-Industry Knowledge Transfer: Literature Review and Unanswered Questions. International Journal of Management Reviews, 3, 285-302. http://dx.doi.org/10.1111/1468-2370.00069

[3] Salter, A.J. and Martin, B.R. (2001) The Economic Benefits of Publicly Funded Basic Research: A Critical Review. Research Policy, 30, 509-532. http://dx.doi.org/10.1016/S0048-7333(00)00091-3

[4] Cohen, W.M., Nelson, R.R. and Walsh, J.P. (2002) Links and Impacts: The Influence of Public Research on Industrial R\&D. Management Science, 48, 1-23. http://dx.doi.org/10.1287/mnsc.48.1.1.14273

[5] Colyvas, J., et al. (2002) How Do University Inventions Get into Practice? Management Science, 48, 61-72. http://dx.doi.org/10.1287/mnsc.48.1.61.14272

[6] Shane, S. (2002) Selling University Technology: Patterns from MIT. Management Science, 48, 122-137. http://dx.doi.org/10.1287/mnsc.48.1.122.14281

[7] Bozeman, B. (2000) Technology Transfer and Public Policy: A Review of Research and Theory. Research Policy, 29, 627-655. http://dx.doi.org/10.1016/S0048-7333(99)00093-1

[8] Mowery, D.C. and Ziedonis, A.A. (2012) Academic Patent Quality and Quantity before and after the Bayh-Dole Act in the United States. Research Policy, 31, 399-418. http://dx.doi.org/10.1016/S0048-7333(01)00116-0

[9] Arrow, K.J. (1962) The Economic Implications of Learning by Doing. The Review of Economic Studies, 29, $155-173$. http://dx.doi.org/10.2307/2295952

[10] Rosenberg, N. (1982) Inside the Black Box: Technology and Economics. Cambridge University Press, Cambridge.

[11] Buenstorf, G. and Schacht, A. (2013) We Need to Talk-Or Do We? Geographic Distance and the Commercialization of Technologies from Public Research. Research Policy, 42, 465-480. http://dx.doi.org/10.1016/j.respol.2012.06.010

[12] Jaffe, A.B., Trajtenberg, M. and Henderson, R. (1992) Geographic Localization of Knowledge Spillovers as Evidenced by Patent Citations. National Bureau of Economic Research, Cambridge, MA. http://dx.doi.org/10.3386/w3993

[13] Mansfield, E. and Lee, J.-Y. (1996) The Modern University: Contributor to Industrial Innovation and Recipient of Industrial R\&D Support. Research Policy, 25, 1047-1058. http://dx.doi.org/10.1016/S0048-7333(96)00893-1

[14] Adams, J.D. (2002) Comparative Localization of Academic and Industrial Spillovers. Journal of Economic Geography, 2, 253-278. http://dx.doi.org/10.1093/jeg/2.3.253

[15] Audretsch, D.B. and Stephan, P.E. (1996) Company-Scientist Locational Links: The Case of Biotechnology. The American Economic Review, 86, 641-652.

[16] Grotz, R. and Braun, B. (1997) Territorial or Trans-Territorial Networking: Spatial Aspects of Technology-Oriented Cooperation within the German Mechanical Engineering Industry. Regional Studies, 31, 545-557. http://dx.doi.org/10.1080/00343409750131686

[17] Brown, J.E. and Hendry, C. (1998) Industrial Districts and Supply Chains as Vehicles for Managerial and Organizational Learning. International Studies of Management \& Organization, 27, 127-157.

[18] Scott, A.J. (1992) The Role of Large Producers in Industrial Districts: A Case Study of High Technology Systems 
Houses in Southern California. Regional Studies, 26, 265-275. http://dx.doi.org/10.1080/00343409212331346961

[19] Zitt, M., Ramanana-Rahary, S., Bassecoulard, E. and Laville, F. (2003) Potential Science-Technology Spillovers in Regions: An Insight on Geographic Co-Location of Knowledge Activities in the EU. Scientometrics, 57, $295-320$. http://dx.doi.org/10.1023/A:1024145920210

[20] Henderson, B. (1970) The Product Portfolio. The Boston Consulting Group, Boston. 
Scientific Research Publishing (SCIRP) is one of the largest Open Access journal publishers. It is currently publishing more than 200 open access, online, peer-reviewed journals covering a wide range of academic disciplines. SCIRP serves the worldwide academic communities and contributes to the progress and application of science with its publication.

Other selected journals from SCIRP are listed as below. Submit your manuscript to us via either submit@scirp.org or Online Submission Portal.
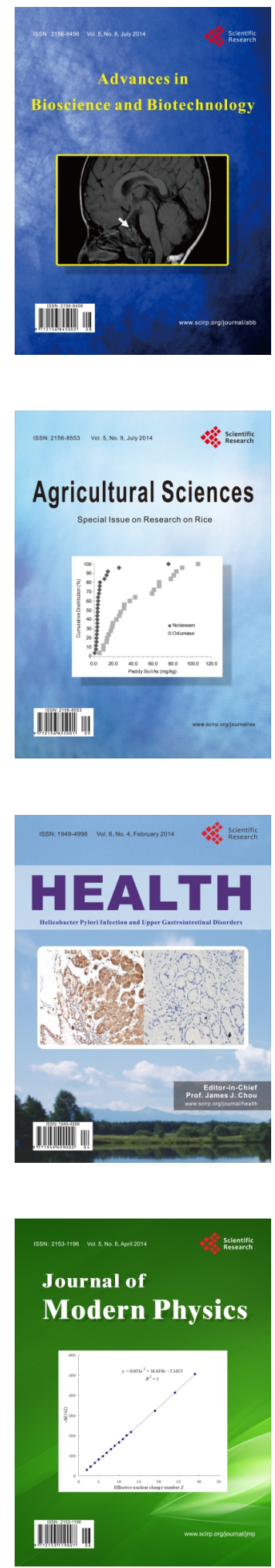
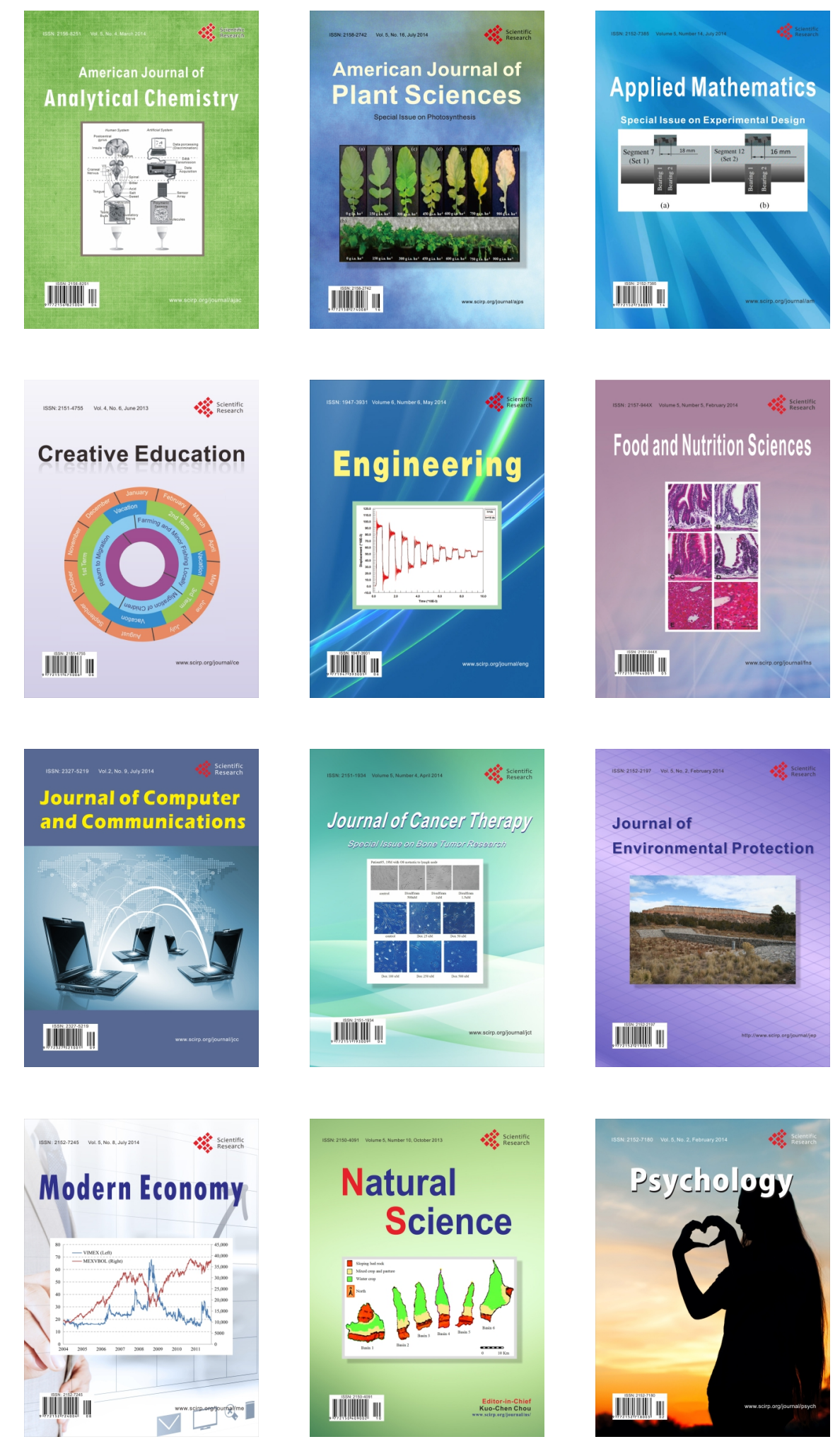